\title{
(RE)SIGNIFICANDO CONCEITOS: FORMAÇÃO CONTINUADA EM SEXUALIDADE E GÊNERO NA PRIMEIRA INFÂNCIA
}

Inaê Elias do Nascimento, Janaina Pereira Duarte Bezerra

Universidade do Oeste Paulista - UNOESTE, Pós Graduação em Educação, Presidente Prudente, SP. E-mail: inaellias@outlook.com

\section{RESUMO}

Temáticas ligadas à sexualidade fazem parte do cotidiano escolar, sendo uma das necessidades formativas de educandos/as e educadores/as. Os Parâmetros Curriculares Nacionais (PCN) propõem que os temas sobre sexualidade sejam trabalhados de maneira transversal, porém os educadores/as sentem-se despreparados na efetivação desses trabalhos; diante de tal fragilidade surge a proposta de formação continua para os/as educadores/as da educação infantil no Fórum Regional da Primeira Infância (FORPEDI). A presente proposta objetiva investigar a trajetória docente através de um questionário aberto e análise das respostas em base linguístico-semiótica, corroborando quais os principais motivos que levaram os/as educadores/as a procurarem a formação continua, evidenciando a fragilidade formativa nos cursos de pedagogia que dificultam na implementação de uma prática pedagógica.

Palavras-chave: Formação continua; Gênero; Educação sexual; Primeira Infância.

\section{(RE)SIGNIFICANDO CONCEITOS: FORMAÇÃO CONTINUADA EM SEXUALIDADE E GÊNERO NA PRIMEIRA INFÂNCIA}

\begin{abstract}
Themes related to sexuality are part of the daily school life, being one of the formative needs of students and educators. The National Curriculum Parameters (PCN) propose that the topics on sexuality be worked in a transversal way, but the educators feel unprepared in the accomplishment of these works; faced with such fragility, the proposal of continuous training for the educators of children's education in the Regional Forum for Early Childhood (FORPEDI) arises. The present proposal aims to investigate the teacher's trajectory through an open questionnaire and analysis of the answers on a linguistic-semiotic basis, corroborating the main reasons that led the educators to seek continuous training, evidencing the formative fragility in the courses. That make it difficult to implement a pedagogical practice.
\end{abstract}

Keywords: Continuing education; Genre; Sexual education; Early Childhood. 


\section{INTRODUÇÃO}

A realidade da educação sexual escolar no Brasil é fruto de um processo histórico que sempre foi objeto de polêmica, no ensino fundamental e principalmente na educação infantil as práticas e estratégias mais frequentes é o silêncio.

Segundo Foucault (2009) temos condenado à sexualidade a escuridão, silenciando os discursos causados pela fragilidade formativa, cultural e religiosa.

O silenciamento em relação à sexualidade no ambiente escolar, em especial na educação infantil, ocorre e torna-se comum por temer-se que, ao abordar tais temáticas, se suscitem mais curiosidades, e, quem sabe, até desperte interesses semelhantes que incidam sobre o paradigma sexualidade. Poderia, ainda encorajar, "determinadas práticas" não coadunadas com a expectativa heteronormativa. (DUARTE, 2015, p. 76)

Salientamos que tanto efetivamente o que se faz como o que não se faz assume caráter de formativo, pois

compreende toda ação ensino-aprendizagem sobre a sexualidade humana, seja em nível de conhecimento de informações básicas, seja em nível de conhecimento e/ou discussões e reflexões sobre valores, normas, sentimentos, emoções e atitudes relacionados à vida sexual (FIGUEIRÓ, 2014, p.44).

Os Parâmetros Curriculares Nacionais (PCN) (BRASIL, 2001) orientarem a trabalhar sexualidade por meio da transversalidade e estão divididos em três blocos: relações de gênero, corpo, matriz da sexualidade e prevenção de doenças sexualmente transmissíveis as Diretrizes Curriculares Nacionais para a Educação Infantil recomendam o trabalho pedagógico sobre gênero, adaptando a faixa etária em que trabalha.

Destarte o tema tem se demonstrado de difícil implementação aparecendo como necessário discursos, educadores/as "geralmente não assumem que estejam educando sexualmente, assim como a criança também não tem consciência de que está recebendo influências da educação sexual" (GAGLIOTTO, 2014, p. 160).

O panorama atual corrobora para que não se efetive prática Educação Sexual, os temas transversais contemplados nos PCNs, denominados "orientação sexual", atualmente, foram suprimidos dos temas integradores do novo documento, Base Nacional Comum Curricular (BNCC).

Mesmo com as tentativas de silenciar os discursos a Educação Sexual ocorre ainda de forma informal ou não intencional quando admite que

ela acontece no dia a dia, nas nossas relações diárias e por meio das quais transmitimos os valores recebidos a partir da cultura em que vivemos e da ES que recebemos. Esta educação é realizada por meio de palavras, de ações intencionais ou por meio dos olhares, dos gestos, da expressão dos sentimentos, das nossas atitudes, dos exemplos que somos para os/as outros/as e até mesmo por meio das coisas sobre as quais não falamos, ou seja, do silêncio (FREITAS E CHAGAS 2013, p.127)

A fragilidade formativa enfrentada por educadores/as, ressalta a necessidade de disciplinas sobre sexualidade como componente curricular dos cursos de licenciatura e de formações continuas: Oliveira; Maio (2012), Figueiró (2014), Bonfim (2010), evidenciando a urgência em cursos de formação continuada de educadores/as em educação sexual com formadores e formandos motivados, livres de preconceitos e com um firme desejo de auxiliar os indivíduos a compreenderem e encarar a sexualidade.

Embora estejamos no século XXI, no que se refere à condição de formação de professores (para os níveis educacionais e as várias áreas disciplinares e mesmo com as orientações mais integradoras das normas vigentes quanto à ainda se verifica a prevalência do modelo consagrado no início do século XX: o esquema de superioridade dos conhecimentos disciplinares sobre os conhecimentos didáticos e metodológicos de ensino, sendo o processo formativo vigente fragmentado em disciplinas estanques, sem interlocuções transversais. (GATTI, 2013, p. 96) 
Em consonância com as necessidades formativas dos profissionais da primeira infância, surge o Fórum Regional da Primeira Infância (FORPEDI) com principal objetivo de fortalecer a formação de educadores fomentando melhoria no atendimento dos educandos/as na região de Presidente Prudente- SP.

No ano de 2015 foi elencada como relevante uma oficina de formação continua sobre sexualidade e gênero para o ano de 2016, destarte este trabalho identificou os conceitos sobre sexualidade e gênero construídos a partir de sua formação acadêmica e as mudanças ocorridas através da formação continua.

\section{METODOLOGIA}

O estudo se estruturou com base numa concepção quanti qualitativa já que de acordo com May (2004, p. 146) produz resultados passíveis de serem quantificados e qualificados, não que tais resultados revelem automaticamente uma verdade melhor do que a outra, mas aos seus pontos fortes e fragilidades na produção do conhecimento. Para tanto, é necessário um entendimento de seus objetivos e da prática.

Apoia-se em autores que primam pela compreensão da realidade humana e social, a partir de uma participação efetiva no campo da pesquisa, intervindo no processo de desenvolvimento do sujeito e observando atentamente as relações sociais, comportamentos, manifestações e expressões corporais e linguagens, com a finalidade de compreender de forma mais elaborada e crítica os fenômenos investigados acerca da realidade em questão (THIOLENT, 2000).

Ludke \& André (1986) esclarecem que a pesquisa de caráter qualitativo enquadra-se na modalidade de reconhecimento da realidade de seus sujeitos, observação cuidadosa, estruturada e sistemática, garantindo um olhar rigoroso sobre o campo de pesquisa e a descrição cuidadosa dos elementos nele identificados pelo pesquisador. Conforme as autoras, a pesquisa qualitativa assume que o conhecimento não é algo acabado, mas uma construção que se faz e refaz constantemente e que possibilita novas respostas e indagações ao longo do processo de pesquisa.

Além disso, caracterizou-se como uma investigação de base linguístico-semiótica, realizada por meio de um questionário aberto com análise tabulação de repostas por conceitos para melhor interpretação dos resultados obtidos.

O estudo foi realizado com 15 professoras, porém somente 8 responderam as seguintes perguntas: sexo, anos de docência, função ou cargo exercido, disciplinas que trabalhavam sexualidade e gênero na docência, fator motivacional para fazer a oficina, concepções anteriores e atuais, e a frequência que os assuntos inerentes aparecem no cotidiano escolar.

Os dados foram tabulados e as informações seguem abaixo.

\section{RESULTADOS}

O gráfico 1 apresenta a frequência em que o assunto foi abordado na graduação 6 entre 8 participantes disseram não ter o assunto abordado na graduação evidenciando a fragilidade em abordar o tema quando necessário. 
Gráfico 1. Houve disciplina sobre sexualidade e gênero na graduação

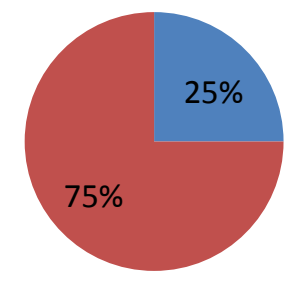

$\because \mathrm{SIM}$

- NÃO

Fonte: Dados trabalhados pelos autores

O gráfico 2 mostra outro dado crucial para compreensão das motivações que fizeram com que escolhessem tal oficina, sendo a dificuldade em lidar com assunto aparece em maior frequência nas falas das professoras.

Gráfico 2. Principais motivações na procura da oficina

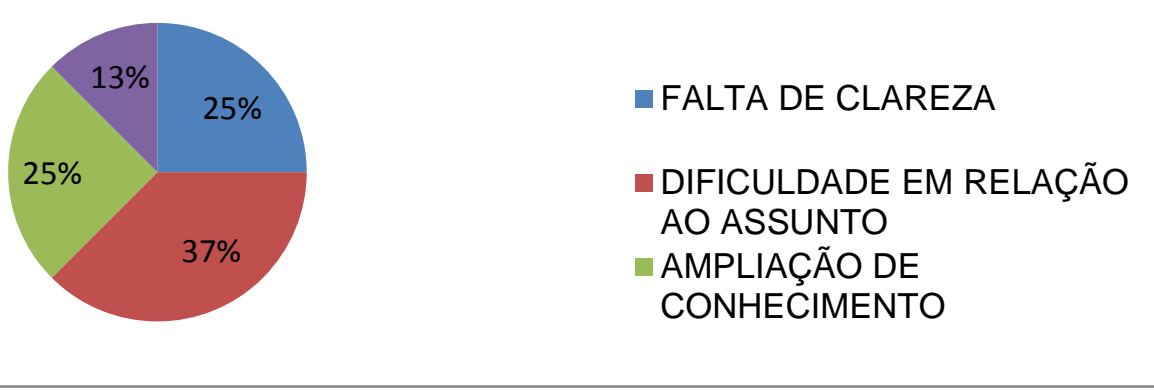

Fonte: Dados trabalhados pelos autores

O gráfico 3 evidencia a opinião anterior de 4 entre 8 professoras não eram claras, ou seja, pouco conhecimento teórico-prático.

Gráfico 3. Opinião anterior à formação continua

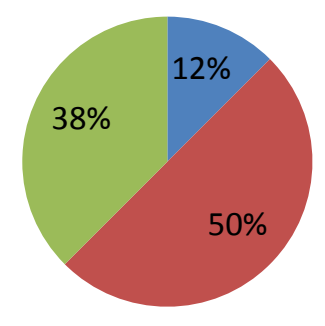

- SENSO COMUM

-FALTA DE CLAREZA

$\square$ DIFICULDADE

Fonte: Dados trabalhados pelos autores

O gráfico 4 mostrará a frequência em que aparece certos conceitos nas respostas das professoras, podendo aparecer mais de um conceito por resposta. 
Gráfico 4. Frequência do uso de conceitos

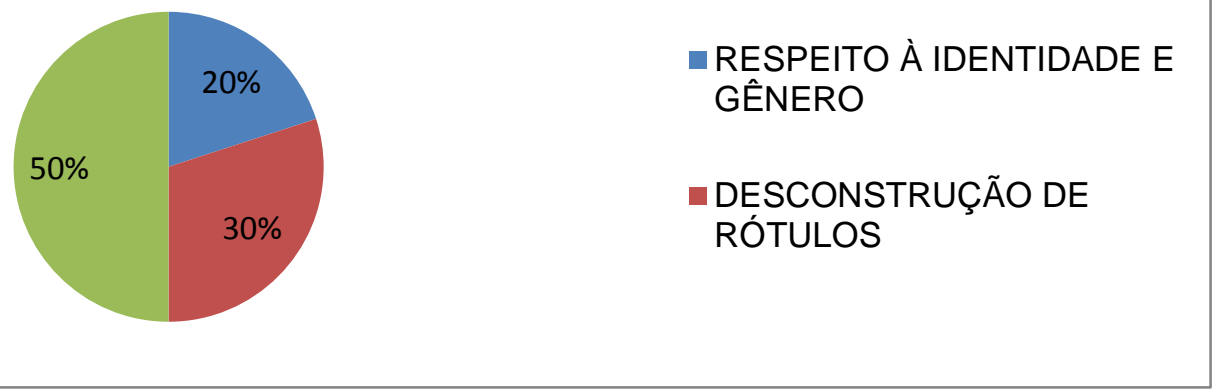

Fonte: Dados trabalhados pelos autores

A tendência central de respostas é a "ampliação de conhecimento", porém todas as respostas aparecem em alta frequência, deixando explicito a carência formativa nos cursos de graduação.

O gráfico 5 traz a frequência em que o assunto é tratado na vida escolar deixando claro que a frequência em que é preciso tratar do tema é maior, 6 entre 8 professores precisam falar sobre estes assuntos deixando claro que apesar de muitas vezes ser silenciado continua se fazendo necessário.

Gráfico 5. Frequência em que o tema é discutido na escola

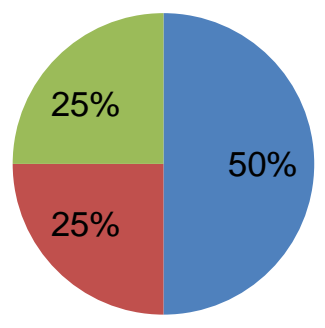

- COM FREQUÊNCIA

- QUANDO

NECESSÁRIO

Fonte: Dados trabalhados pelos autores

\section{DISCUSSÃO}

As professoras que aderiram á proposta de participar da oficina atuam-na educação de crianças de 0 a 5 anos, a oficina ministrada contou com a participação alunas de graduação, professoras, coordenadoras e gestoras todas do sexo feminino e lecionam em média á 10 anos.

Durante o ano letivo tiveram 8 encontros com duração de 4 horas; os procedimentos utilizados foram exposição de conceitos, estudo de relatos de experiências, debates, leitura de imagens, textos e vídeos, discussão sobre violência e desigualdades implicadas com o corpo, gênero e sexualidade articuladas com heteronormatividade, sexismo, eroticidade, prazer, desejo, sentimentos, valores, autoestima, consciência corporal, reprodução humana, direitos das crianças, politicas educacionais, atividades e práticas educativas.

As respostas apontaram um dado preocupante e passível de aprofundamento foi que as 6 entre 8 entrevistadas disseram não ter tido nenhuma informação e/ou disciplina que abordasse o tema "sexualidade e gênero na graduação", outras 2 disseram ter tido "algumas considerações na disciplina de psicologia", evidenciando a exiguidade com que o tema é tratado dentro da graduação, evidenciando a necessidade de reestruturação dos cursos de Pedagogia como apontam os estudos de (GATTI, 2012, 2013, 2014).

A falta de formação inicial é o principal fator da escolha por esta oficina, as palavras elencadas foram: falta de clareza, dificuldade, relevância do assunto e ampliação dos 
conhecimentos denotam a dificuldade que estas professoras têm em procurar um eixo norteador; conhecendo apenas os materiais oficiais que apenas ressaltam a importância, mas que não norteiam para a prática é necessário aporte para que se construa uma "reflexão pessoal sobre o tema e também por uma revisão dos próprios valores, dos próprios sentimentos, dos possíveis tabus e preconceitos existentes a esse respeito" (FIGUEIRÓ, 2009, p. 166).

Considerando o aporte teórico como fundamental para auxiliar no desenvolvimento da prática educativa, o senso comum compreende os saberes, a falta de clareza como falta de um eixo norteador para responder questões inerentes a sexualidade e a dificuldade como aquelas educadoras que não tinham conhecimento e não sabem por onde começar.

As educadoras sentem se desconfortáveis para responder questões advindas dos educandos/as, executar um trabalho de prevenção às vulnerabilidades, sexualidade e gênero, por falta de suporte focados na educação de crianças de 0 a 5 anos. Há também os signos culturais proveniente da religião e da história fortemente incrustada, impedindo- os de executar este trabalho, segundo Furlani $(2007$, p. 13)

A ausência dessa temática na quase totalidade dos cursos de formação de professores e a falta de tradição familiar na sua discussão, se somam aos modelos de disciplinamento, censura e conservadorismo de diversos discursos sociais, quer sejam eles religiosos, midiáticos, jurídicos, médicos, governamentais, escolares.

A prática do silêncio não causa conflitos, ressaltando a politica atual que tem suprimido gênero e orientação sexual dos documentos sobre Educação no Brasil, ressaltamos a mudança no Plano Nacional da Educação (PNE) e em 2017 e a Base Nacional Comum Curricular (BNCC) teve retirados a palavra gênero e orientação sexual pelo (CNE) órgão que está responsável por elaborar um parecer antes da homologação.

Sendo a educação infantil etapa em que a criança constrói a concepção de gênero, sem formação teórica e prática o professor acaba por orientar utilizando-se de discursos socialmente e historicamente pré-estabelecidos e normalizadores.

Sobre a frequência que o assunto é tratado na escola, 6 entre 8 professoras disseram discutir sobre sexualidade e gênero com frequência ou quando necessário evidenciando a importância da formação continua com bases teóricas contribuindo para implementação de uma prática pedagógica crítica .

\section{CONCLUSÃO}

Podemos concluir que a fator principal para as professoras não desempenharem trabalhos sobre sexualidade e gênero são a falta de documentos oficiais e de não saber como buscá-lo, questões inerentes a sua formação social e religiosa, falta de espaço nos cursos de licenciatura dificultam na prática educativa.

É indubitavelmente necessário de formação sobre sexualidade e gênero nos cursos de licenciatura assim como a elaboração de materiais oficiais que norteiem a prática pedagógica desvelando tabus que permeiam os profissionais da educação que findam por perpetuar uma pedagogia do silêncio.

A formação contínua realizada na oficina pode propiciar conhecimento para práxis educativa e fez com que os profissionais da educação pudessem refletir sobre os conceitos de gênero, corpo e sexualidade; discutir as manifestações, vivências e percepções das crianças sobre sexualidade e erotismo; as várias dimensões experienciais dos corpos: consciência corporal, prazer, autoestima; as possibilidades de prevenção do abuso sexual das crianças; refletir sobre as possibilidades de um trabalho crítico do sexismo e da heteronormatividade desde a infância; proporcionar o conhecimento de experiências com atividades educativas. 
Figueiró (2014, p.32) afirma que, "envolver-se em um processo de formação continuada, embasado na prática reflexiva, auxilia o professor em seu desenvolvimento profissional e na melhoria de sua prática pedagógica".

A oficina auxiliou estes educadores/as a pensar sua práxis educativa, compreendendo que não há formula pronta pois a

prática educacional é prática social com significado e não pode ser tomada como simples receita, ou confundida com tecnicismos modeladores. É necessário transcender o senso comum retificado, superar os sentidos usuais atribuídos às práticas pedagógicas condenadas por muitos sem defesa (e muitas vezes sem argumentos). Prática pedagógica, por ser pedagógica, é ação política, de cidadania, comportando formas de ação guiadas por seus fundamentos, sejam filosóficos sejam científicos. Implica fazer pensando e pensar fazendo, implica saber fazer e porque fazer, ou seja, implica uma praxiologia. (GATTI, 2013, p. 55)

As experiências vividas nessa oficina, as trocas de informações, experiências, dúvidas e conhecimentos mostraram que não há distanciamento do que se aprende com o que se ensina e que deve se investir na formação continua pois ela é inacabada ao educador/a, cabendo a ela abranger tanto o caráter informativo quanto formativo (FIGUEIRÓ, 2014), assumindo caráter emancipador em sua metodologia de ensino e para seu autoconhecimento.

O contexto atual nos mostra o quanto estamos caminhando a passos lentos, mudanças devem começar a partir do currículo de formação docente, tais ações permitiram posicionamento pedagógico e politico em relação ao trabalho do/a educador/a da infância com o corpo, gênero e sexualidade.

\section{REFERÊNCIAS}

BRASIL. Ministério da Educação. Parâmetros curriculares nacionais: pluralidade cultural e orientação sexual: temas transversais. Rio de Janeiro: DP\&A, 2001.v. 10.

BONFIM, Cláudia. (2010). Educação Sexual e formação de professores: da educação sexual que temos à educação que queremos. 1a edição. João Pessoa-PB: UFPB. BRITTOS, Eritânia Silmara de; SANTOS, ISSN: 1807 - 8214 Revista Ártemis, vol. XXV no 1; jan-jun, 2018. pp. 274-291 290.

FIGUEIRO, M. N. D. Educação sexual : múltiplos temas, compromisso comum. (org.) Educação Sexual: como ensinar no espaço da escola. - Londrina: UEL, 2009. 190p.

. Formação de educadores sexuais: adiar não é mais possível. 2. ed. - Londrina:

Eduel, 2014.

FOUCAULT, M. História da Sexualidade I: a vontade de saber. Rio de Janeiro: Graal, 2009.

FREITAS, Dilma Lucy de; CHAGAS, Isabel. Educação Sexual em Portugal: a formação de professores como caminho. Um relato de experiências. In RABELO, Amanda Oliveira; et al. Formação docente em gênero e sexualidade: entrelaçando teorias, políticas e práticas. Petrópolis: FAPERJ, 2013. p. 123-142.

FURLANI, J. Mitos e tabus da sexualidade humana: subsídios ao trabalho em educação sexual. 3a ed. Belo Horizonte: autêntica, 2007.

GATTI, Bernardete Angelina. Por uma política nacional de formação de professores. São Paulo: EDUNESP, 2013. 
GAGLIOTTO, G. M. A Educação Sexual na Escola e a Pedagogia da Infância: Matrizes Institucionais, Disposições Culturais, Potencialidades e Perspectivas Emancipatórias. Jundiaí, Paco Editorial: 2014.

LÜDKE, Menga; ANDRÉ, Marli E.D.A. Pesquisa em educação: abordagens qualitativas. São Paulo: EPU, 1986.

MAY, T. Pesquisa social: questões, métodos e processos. 3. ed. Porto Alegre: Artmed, 2004.

SILVA, L. M. M.; SANTOS, S. P. Sexualidade e Formação Docente: representações de futuros professores/as de Ciências e Biologia. VII Encontro Nacional de Pesquisa em Educação em Ciências, Campinas, 2011.

THIOLLENT, M. Metodologia da pesquisa-ação. São Paulo: Cortez. 2000. 